\title{
How can the major European oil and gas companies continue to be competitive? A comparative analysis between 2000 and 2008
}

\author{
Othman Cole \\ ESCP Europe Business School, \\ 527 Finchley Road, \\ London NW3 7BG, UK \\ Email: ocole@escpeurope.eu
}

\begin{abstract}
This paper uses the resource-based view (RBV) of the firm to analyse the performance of the major European oil and gas companies between 2000 and 2008. This period covers a relatively stable era in the oil and gas industry, just after the intense merger activities and consolidations in the industry in the late 1990s and just before the collapse of oil prices at the onset of the global financial crisis in late 2008. This study uses comparative research methodology and data from the Energy Intelligence database to analyse the performance of the major European oil and gas companies in the context of both property and knowledge-based resources. New arguments put forward include the view that these oil and gas companies should focus on developing their knowledge-based resources, both knowledge creation and knowledge application, in order to maintain and improve competitiveness in the long run.
\end{abstract}

Keywords: competitiveness; comparative advantage; oil and gas; petroleum; Europe; European; resource-based view; RBV; knowledge-based resources; property-based resources.

Reference to this paper should be made as follows: Cole, O. (2016) 'How can the major European oil and gas companies continue to be competitive? A comparative analysis between 2000 and 2008', Int. J. Competitiveness, Vol. 1, No. 1, pp.53-70.

Biographical notes: Othman Cole is an Assistant Professor of Finance at ESCP Europe Business School. He was a Research Associate at Judge Business School, investigating the resource-based view of oil and gas companies as well as the key challenges and opportunities facing national oil companies (NOCs). He was also a Postdoctoral Research Fellow at the Cambridge China Development Trust. He received his $\mathrm{PhD}$ and his MPhil in Finance, both from Judge Business School, University of Cambridge. He holds an MSc in International Securities, Investment and Banking as well as an MEng in Computer Systems Engineering.

\section{Introduction}

The major premises of the resource-based view (RBV) of the firm are that firms are bundles of idiosyncratic resources and capabilities and those firms with valuable, rare, in-imitable and non-substitutable (VRIN) resources and capabilities outperform in their 
industries (Schmidt and Keil, 2013; Newbert, 2008; Barney, 2001; Dierickx and Cool, 1989; Wernerfelt, 1984, 1995, 2013). Drawing on Barney (1991), Miller and Shamsie (1996) define property-based resources as appropriable resources controlled by the corporation through property rights, and in contrast, knowledge-based resources are those "protected from imitation not by property rights but by knowledge barriers", and often include technical, creative or collaborative skills (1996, p.522).

The literature that links the RBV of the firm to the oil and gas industry, which lends itself well to this type of analysis given the changes the industry has experienced, is very limited. A few studies have focused only on property-based resources such as oil fields (Kim and Mahoney, 2002) or focused only on knowledge-based resources such as employees and knowledge creation and application (Gardner et al., 2012; Nag and Gioia, 2012; Grant, 1996). Other studies have looked at the relationship between performance and environmental concerns and climate change (Levy and Kolk, 2002; Russo and Fouts, 1997). This study uses data from the Energy Intelligence database and addresses a gap in the literature by analysing the performance of the major European oil and gas companies in the context of both property-based and knowledge-based resources.

Given the lack of analysis of both property-based and knowledge-based resources in the context of oil and gas companies in prior studies, this study is considered relevant as it provides new insights by taking into account both kinds of resources. From a theoretical point of view, this study adds to the literature by connecting the arguments developed by Grant (1996) regarding the relevance of not just knowledge creation but also knowledge application to the long run performance and competitiveness of oil and gas firms. From a practical point of view, this study discusses the practices of the oil and gas companies analysed in the context of VRIN resources and capabilities, which adds to the literature from an industry perspective.

This study is conducted in the oil and gas industry because energy is one of the key sectors of the global economy and its significance is expected to continue as our lives become increasingly dependent on technology. At present, the oil and gas industry is by far the most dominant industry in the energy sector and our reliance on hydrocarbons will arguably continue for many decades despite efforts at developing renewable energies. Therefore, the motivation for this study is deeply rooted in the relevance of the oil and gas industry as a key source of our energy needs for the foreseeable future. It is therefore important to understand the major companies in this industry by investigating their performance and competitiveness in the context of RBV.

Further, the oil and gas industry presents serious policy-making challenges across Europe. For instance, how much should the oil companies be taxed when oil prices are high? Will this be at the expense of reinvesting profits into R\&D activities and increasing their knowledge-based resources? Also, should shale gas be developed and if so how should it be regulated? What are the trade-offs between job creation and human capital development on the one hand and strong environmental concerns on the other? It is therefore important to understand what the key areas are that the major European oil and gas companies need to develop in order to be competitive in the new era of carbon pricing and arguments for grid parity.

This paper therefore uses the RBV framework to conduct a comparative analysis of the major European oil and gas companies. The study will look at six companies namely BP, Eni, Repsol, Shell, Statoil and Total, and identify which resources are drivers and determinants of their competitive advantage and financial performance. These six companies account for about $86.8 \%$ and $85.9 \%$ of the total liquids and gas reserves 
and the total liquids and gas production respectively of the European oil and gas companies in the Energy Intelligence top 100 ranking of the world's oil companies.

Drawing on the framework of property-based and knowledge-based resources, the paper will analyse six resource categories of oil and gas companies namely annual capital expenditure, annual changes in liquids and gas reserves, annual replacement ratios, refinery distillation capacity and number of service stations, number of employees and net income per employee, and annual levels of drilling activity in exploration and development with a disaggregation of successful and unsuccessful wells drilled. These six categories are chosen due to the availability of data, other resource categories are discussed for possible extension to this study.

Section 2 provides an overview of the literature. Section 3 outlines the research methodology and presents the RBV framework. Sections 4 and 5 analyse the property and knowledge-based resource measures respectively. Section 6 discusses areas of further research. Section 7 highlights the implications for management practice, and Section 8 concludes.

\section{Literature review}

Miller and Shamsie (1996) argue that knowledge-based resources are associated with success in 'difficult' environments, whereas the opposite is true for property-based resources. The argument being put forward is that knowledge-based resources will become more critical for success in the future compared to property-based resources. This paper will therefore compare how the major European oil and gas companies perform relative to each other within the framework of the two kinds of resources. In Miller and Shamsie (1996), property-based resources included the number of film theatres and the number of film stars under long-term contracts, and knowledge-based resources included the number of academy awards and the history of per film production costs.

In relation to the oil and gas industry, one of the limited studies in this area investigated the impact of property rights on the RBV of value creation in the case of an oil field. Kim and Mahoney (2002) start from the premise that resource-based theory implicitly assumes that property rights to resources are secure. They then relaxed this assumption in the case of an oil field with different equity stakeholders but a single firm that develops and operates the field, and in which there might be difficulties in establishing property rights that create or enhance the realised economic value of the resources. They argue that a full resource-based analysis of value creation must incorporate the role of property rights. In essence, property rights play an important role in the resource-based analysis of value creation.

In contrast, Grant (1996) investigated the knowledge-based theory of the firm and argues that earlier literature emphasised knowledge creation without much discussion of knowledge application and the role of the individual. He argues that if the primary resource of the firm is knowledge, if this knowledge resides and is owned by employees, and if much of this knowledge can only be exercised or applied by the individuals who possess it, then knowledge application is just as important. However, he admits that focusing only on knowledge application and disregarding knowledge creation is a serious 
limitation and therefore argues for a comprehensive knowledge-based theory of the firm that embraces both knowledge creation and knowledge application.

In a study of business groups in emerging economies, Guillen (2000) used a RBV analysis to investigate and explain how business groups in emerging economies with businesses in diversified industries including oil and gas accumulate the capability for repeated industry entry into a number of industries. He argues that such a capability can be regarded as a valuable, rare, and in-imitable skill and can be valuable only as long as asymmetric foreign trade and investment conditions prevail. His findings support the view that entrepreneurs and firms in emerging economies find it strategically sustainable to diversify into new industries by leveraging their property and knowledge-based resources.

Another strand of the literature relating to the RBV and the oil and gas industry is the issue of climate and environmental change. Russo and Fouts (1997) draw from the RBV of the firm and hypothesise that environmental performance and economic performance are positively related, and that industry growth moderates this relationship, with the returns to environmental performance higher in high-growth industries. They studied 243 firms over two years and their results confirm their hypothesis that "it pays to be green" and that this relationship strengthens with industry growth.

In a later study, Levy and Kolk (2002) investigated the strategic responses to global climate change by multinational oil and gas companies. They analysed the responses of oil multinationals to climate change and found that local context did influence the initial corporate reactions, but as the issue matured, convergent pressures did predominate.

\section{Research methodology and RBV framework}

This study uses comparative research methodology and descriptive statistics to conduct an analysis of the major European oil and gas companies. Comparative research methodology is adopted as it enables the comparison of quantitative data of two or more entities with a view to discussing and analysing qualitatively the findings and some unexplained issues about one or all of the entities being compared (Deutsch, 1987; Clasen, 2004).

The data for each of the six companies is obtained primarily from the Energy Intelligence database of the world's top 100 oil companies from 2000 to 2008. The data is used as proxies to capture and analyse the key aspects of the property-based and knowledge-based resources that are investigated in this study. Summary statistics are used to aggregate the data and the comparative results are presented using tables, graphs, charts and scatterplots.

This paper will analyse the following resources namely annual capital expenditure, annual changes in liquids and gas reserves, annual replacement ratios, refinery distillation capacity and number of service stations, number of employees and net income per employee, and annual levels of drilling activity in exploration and development outlining total wells drilled with a disaggregation of successful and unsuccessful drilling.

With regards to building up property-based resources, a key factor for oil and gas companies is their level of investment in exploration, development, and production. A measure used to capture some aspects of this is their annual capital expenditure, with upstream and downstream disaggregation. This measure gives us an insight into the 
levels of investment undertaken by the companies at both the upstream (reserves increment) and downstream (refinery and retail infrastructure) levels.

Technology is an important factor in the petroleum industry and continues to play a crucial role at all stages in upstream oil and gas activities. This includes conducting initial seismic studies and their interpretations to establish whether a particular acreage has good prospects for oil and/or gas reserves; drilling exploratory wells to establish the type and scale of reserves; developing oil and gas fields to achieve efficient production; and maintaining fields for optimal production.

These upstream technology challenges can be particularly severe in offshore and deepwater acreages as well as in new onshore oil provinces that have limited geological data. Mature fields also pose real technology challenges for oil and gas companies as they seek to maintain output while production levels peak and start to decline. This includes efforts such as enhanced oil recovery and pumping gas to maintain pressure for a continuous flow. As the 'easy' reserves become exhausted, it will become more technically difficult to continue production from existing fields and to establish new ones.

Therefore, a measure used in this analysis is the companies' annual changes in liquids and gas reserves. Since this is an absolute measure, it does not give a clear indication of the size of the new reserves (or depleted reserves) relative to the companies' existing reserve base or production levels. As a result, a further comparative measure used is the annual replacement ratios, which gives a better measure and understanding of reserves changes in relation to the companies' existing production levels. We can also take into account global supply and demand trends and its impact on the companies' changes in reserves but since this will impact all companies, albeit to different degrees, this comparative analysis will focus on the companies' relative performance in terms of their replacement ratios. On the downstream side, a measure used is the amount of refinery distillation capacity and the number of service stations.

To capture some aspects of the knowledge-based resources of the companies, a measure used to provide some insight into the level and relative performance of their employees is the number of employees and net income per employee. This measure gives us some understanding of the output and efficiency of the companies in the context of knowledge-based resources. The argument is that the technical and management capabilities of the employees of an oil and gas company determine to a large extent its level of success. This includes geologists, petroleum and reservoir engineers, project managers, senior managers, marketing executives, and finance specialists.

A key human resource challenge for oil and gas companies is to be able to attract, train, and retain talented young professionals. To address this challenge, the argument is that they must identify the key technical and management roles that are critical and vulnerable to skills shortage and ensure that recruitment into these key areas is attractive enough in terms of training, financial rewards and future prospects. A further measure used to capture the level of technical knowledge and expertise of the employees of the companies is the companies' annual levels of drilling activity, which due to the high costs involved per well implies a certain level of confidence about the prospects of the well and also importantly about the skills of the geologists and engineers. This analysis will look at the total number of wells drilled with a disaggregation of successful and unsuccessful drilling for both the exploration and development stages. This measure reveals the success rate of the companies in both exploration and development drilling. 


\section{Property-based resources}

\subsection{Annual capital expenditure}

The total capital expenditure for the nine years from 2000 to 2008 for the six companies is shown in Figure 1. This chart shows us that BP spent the most over the period at around US\$ 200 billion, followed by Shell at around US\$ 176 billion. However, if we look further into the split between upstream and downstream expenditure in Figure 2, we see that Shell spent marginally more in upstream, about US\$ 6 billion more, perhaps reflecting the higher prospects of its upstream assets or perhaps an indicator that it needed to invest more in upstream to replenish its increasingly depleted/revised reserve base. In contrast, BP spent over US\$ 12 billion more in downstream highlighting its focus on revamping and rebranding its service stations to reflect the company's new direction of 'Beyond Petroleum'.

Figure 1 Total CapEx 2000-08 (see online version for colours)

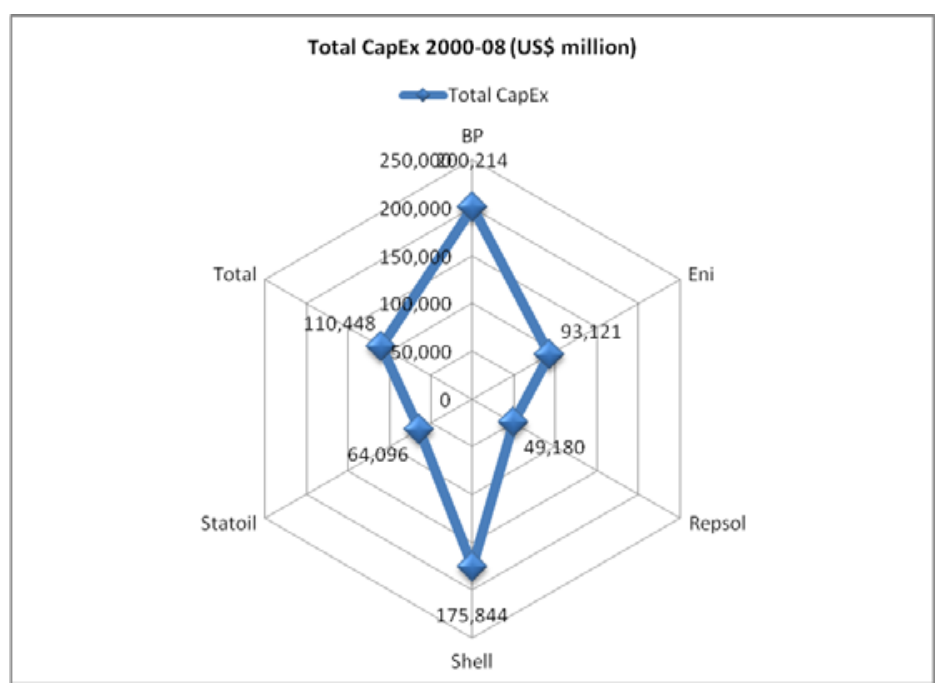

Total and Eni showed a balanced mix of upstream and downstream spend with Total spending relatively more in downstream. However, the striking feature is that of Statoil which spent about $88 \%$ of its US\$ 64 billion total expenditure in upstream, which reflects its strong focus on upstream offshore activities. In contrast, Repsol, which has the lowest total expenditure among the six companies at US\$ 49 billion, spent almost US\$ 11 billion in downstream, more than Eni and Statoil. What does this strategy of a more upstream or more downstream focus mean for the long-term profitability for these companies? 
Figure 2 Upstream and downstream CapEx 2000-08 (see online version for colours)

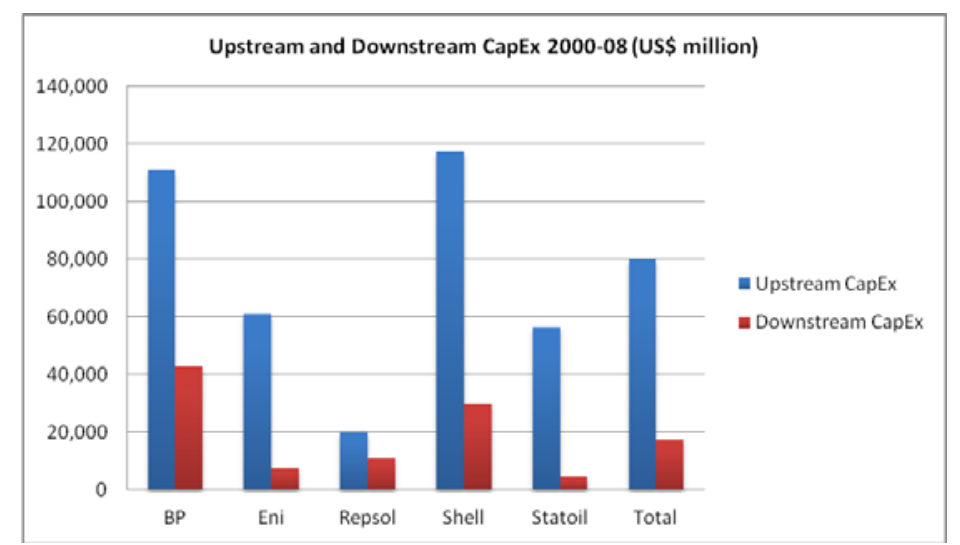

\subsection{Annual changes in liquids and gas reserves}

In the upstream domain, a key measure is the change in liquids and gas reserves and Figure 3 shows us the cumulative change for both oil and gas for the six companies from 2000 to 2008. The best performer was BP with a total oil reserves increment over the period of about 2.8 billion barrels (bbl) and a total gas reserves increment of about 9.7 trillion cubic feet (tcf). Eni and Total fared well with the former performing marginally better, especially in oil as Total experienced a decline over the period of about 1.2 billion barrels in its oil reserves.

The worst performer, in terms of reserves increment, was Shell despite spending the most among the six companies with a cumulative upstream capital expenditure of US \$ 117 billion. Shell's oil reserves declined by about 5.1 billion barrels and more dramatically its gas reserves declined by more than $11.8 \mathrm{tcf}$ over the period. This was primarily due to significant revisions to its reserve base, especially in West Africa. In 2003 alone, Shell announced downwards revision of about 3.5 billion barrels of oil and about 8.5 tcf of gas, particularly from its Nigerian assets. Figure 4 shows the annual average changes for the six companies for both oil and gas and further helps to depict the contrast in their performance. 
Figure 3 Total change in oil and gas reserves 2000-08 (see online version for colours)

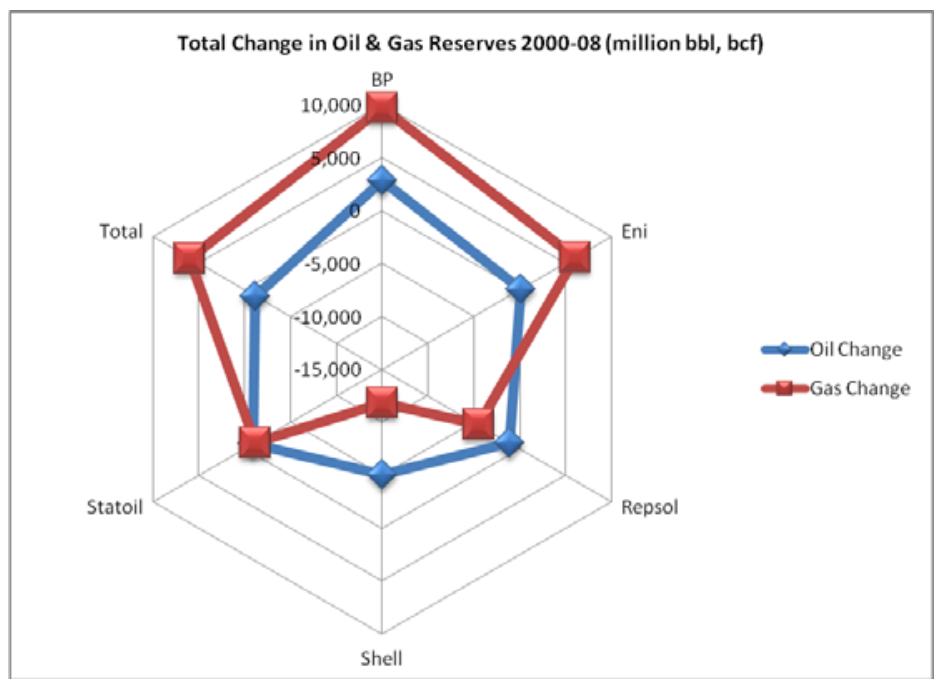

Figure 4 Annual average change in oil and gas reserves 2000-08 (see online version for colours)

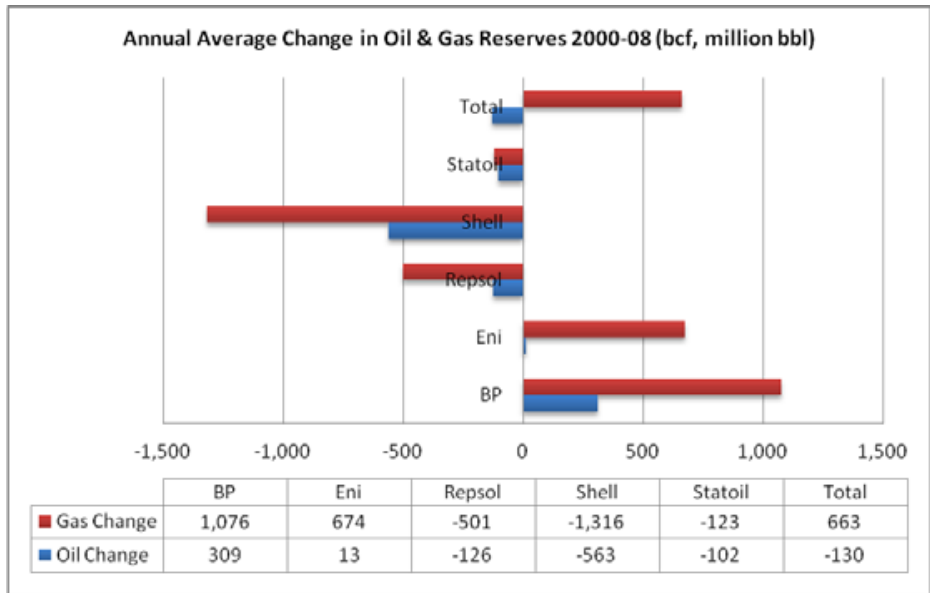

\subsection{Annual replacement ratios}

To gain a deeper understanding of the companies' changes in oil and gas reserves, one must also look at reserve replacement ratios which gives further insight into how much new reserves are added relative to the production levels of the respective companies. This is shown in Figure 5, which compares the annual average replacement ratios for both oil and gas for the six companies between 2000 and 2008. For example, we see that despite BP's oil reserves increment of about 2.8 billion barrels over the period, its increase in oil production outpaced its increase in oil reserves, as its annual average oil replacement ratio over the period was $63 \%$. In contrast, its annual average gas replacement ratio was $142 \%$ highlighting a sustainable increase in its gas reserves. 
When looking at Repsol's replacement ratios, we see that it was about breaking even in oil with a replacement ratio of $102 \%$ but its gas replacement ratio was a striking $261 \%$. This was due to the significant gas reserve increases in 2000 and 2001, which yielded replacement ratios of 987 and $912 \%$ respectively. Eni showed a sustainable reserve increment in both oil and gas with annual average replacement ratios of 119 and 144\% respectively. Total fared less well but its performance was relatively better in gas with a replacement ratio of $113 \%$ compared to oil, for which it was barely breaking even in terms of new reserves relative to production levels with an annual average replacement ratio of $97 \%$.

Figure 5 Annual average oil and gas reserve replacement ratios 2000-08 (see online version for colours)

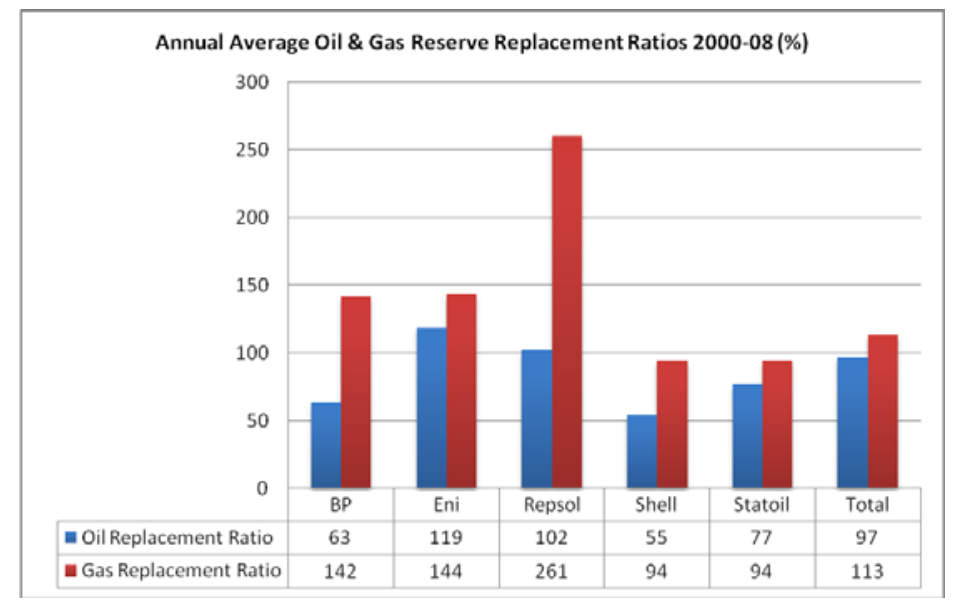

\subsection{Refinery distillation capacity and number of service stations}

In the downstream domain, the key measures shown in Figure 6 of refinery distillation capacity and number of service stations capture the level of property-based resources for the six companies between 2000 and 2008. We see that despite BP's cumulative downstream capital expenditure of US\$ 43 billion, over US\$ 12 billion more than Shell's, it has on an annual average basis significantly less number of service stations at 26,144 compared to Shell's 35,778. In fact, if we look at the final year's figures in 2008, BP had 22,600 service stations compared to Shell's 45,000. What does this tell us about both companies, is BP focusing more on higher value locations and spending more on refurbishment and branding? How profitable is upstream versus downstream and is it worthwhile to be as vertically integrated?

Statoil is the least vertically integrated of the six companies and has spent only $7 \%$ of its cumulative capital expenditure between 2000 and 2008 in downstream. It has the least number of service stations at just over 2,000 and its refinery distillation capacity is the smallest at an annual average of only 319 thousand barrels per day. In contrast, Shell and BP had an annual average refinery distillation capacity of 3.9 and 3.0 million barrels per day respectively. Given that historically downstream has been less profitable than upstream, should companies with successful upstream activities adopt Statoil's model by focusing predominantly on upstream and leaving the less profitable downstream activities 
for others? Or is there some hidden value in maintaining significant downstream operations for the future?

Figure 6 Annual average number of service stations and refinery distillation capacity 2000-08 (see online version for colours)

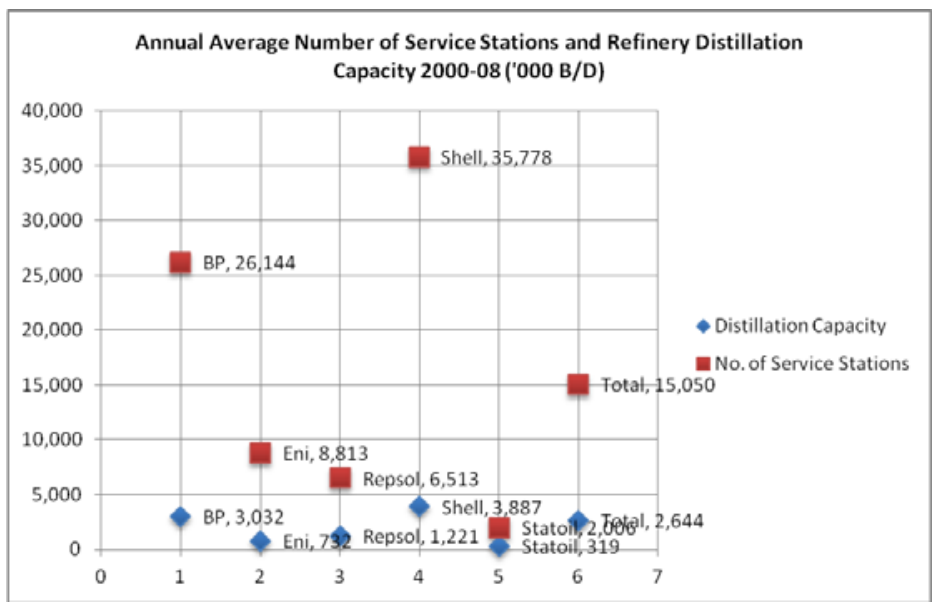

Some of the findings with regards to the property-based resources are consistent with Kim and Mahoney (2002), which looked at oil field unitisation. The data for the six companies analysed in this study illustrate the importance of property-based resources given by the companies' annual capital expenditures. Over the nine years from 2000 to 2008, Shell spent the most in upstream activities because it had to replenish its depleting and dramatically downward-revised oil and gas reserves. We see this in the rapid decline of annual changes in its liquids and gas reserves as well as its annual replacement ratios for both oil and gas. In downstream, BP spent the most as it was refurbishing and rebranding its service stations.

High levels of capital expenditure require high levels of financial capital. Given their sizes, it can be argued that BP and Shell have an advantage in raising capital at lower costs. But is this cheaper access to capital a VRIN resource? It is valuable because the lower cost of capital creates added value in the Net present value (NPV) of projects. However, it can be argued that it is not rare, in-imitable, and non-substitutable because other companies can have access to the capital markets, can explore other methods of capital raising, and can substitute financial capital with other forms of financing structures. So one can argue that competitive advantages derived primarily from access to capital, which itself is not a VRIN resource, cannot be considered VRIN resources. This includes for instance number of service stations and refinery capacity. However, for new reserves and replacement ratios, one has to also look at the knowledge-based aspect, which is analysed in the following section. 


\section{Knowledge-based resources}

\subsection{Number of employees and net income per employee}

The annual average number of employees and the net income per employee of the six companies between 2000 and 2008 is shown in Figure 7. We see that Total appears to have the highest average number of employees at just over 110,000 but this is due to the relatively high employee numbers of over 120,000 from 2000 to 2002. This swelling of its ranks can be attributed to the two acquisitions of Petrofina and Elf Aquitaine in 1999 and 2000 respectively. Total has since trimmed its employee numbers as evident from the final year's figures in 2008, when it had less than 97,000 employees, which was less than Shell at 120,000 but more than BP at 92,000.

In terms of efficiency per employee, Total did not fare as well with the second lowest annual average net income per employee of US\$ 108,611, only better than Repsol. In fact, Total's efficiency only really picked up from 2004, probably as a result of trimming employee numbers after the acquisitions as well as developing its higher margin upstream business. The best performer in terms of employee efficiency was Shell with an annual average net income per employee of US\$ 182,667, followed by Statoil at US\$170,875 which we know focused predominantly on upstream. Was this performance based on the in-imitable knowledge and expertise of their employees or was it based on the high-yielding oil and gas assets that they held? In other words, was this due primarily to knowledge-based or property-based resources or was it a combination of the two? As discussed in Section 6, the strategic value of the two kinds of resources differs depending on the kind of environment in which they are used.

Figure 7 Annual average number of employees and net income per employee 2000-08 (see online version for colours)

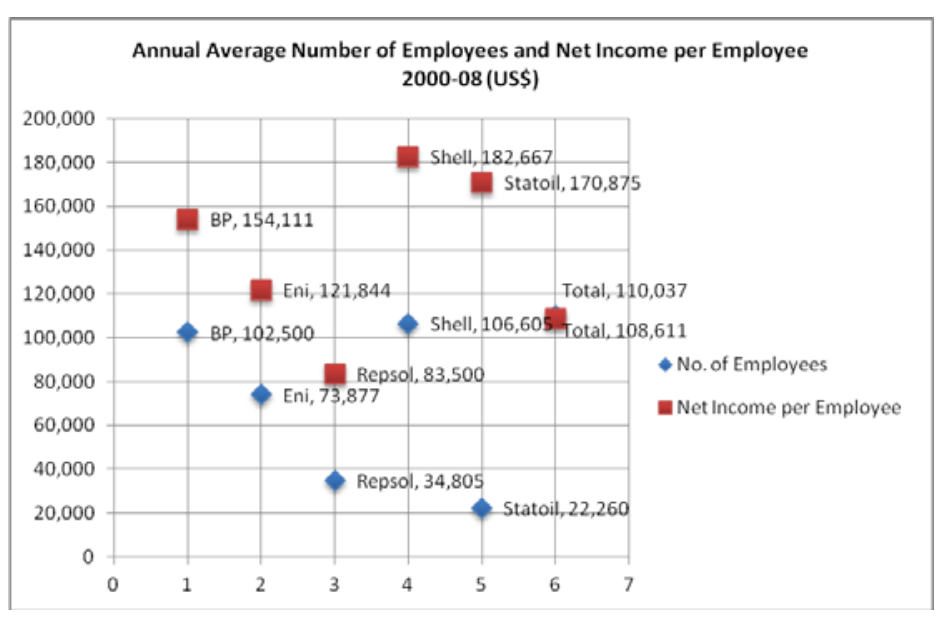




\subsection{Annual levels of drilling activity}

Figure 8 shows the cumulative exploration drilling activity for four of the companies (as data was not available for Eni and Repsol) from 2000 to 2008 . We see that Shell was by far the most active company drilling 751 wells, almost double the number for BP, which is at second place with 382. Shell's drilling activity accelerated from about 2006 when it started to drill 3 to 4 times as many exploration wells as BP. This shows that despite Shell's significant downstream operations by having almost doubled the number of service stations of BP, it does invest significantly in upstream as well and therefore pursues a well-balanced mix of upstream and downstream. Statoil and Total are roughly at par with cumulative exploration wells of 141 and 175 respectively, despite Statoil's size as a company being much smaller than Total. This further reflects Statoil's focus on upstream.

The number of successful wells drilled in relation to the total number of wells drilled gives us an idea of how good these companies are and the level of technical, collaborative and project management expertise of their employees. This annual average success rate over the period is shown in Figure 10 and we see that BP, Shell and Statoil are at par at $64 \%$, and Total at $58 \%$. Considering that the business of finding new reserves is the lifeblood of any oil and gas company, and that this is becoming increasingly difficult as most of the new reserves are in technically challenging regions, how well placed are the European oil and gas companies in terms of their knowledge-based resources in exploration?

Figure 8 Total exploration drilling 2000-08 (see online version for colours)

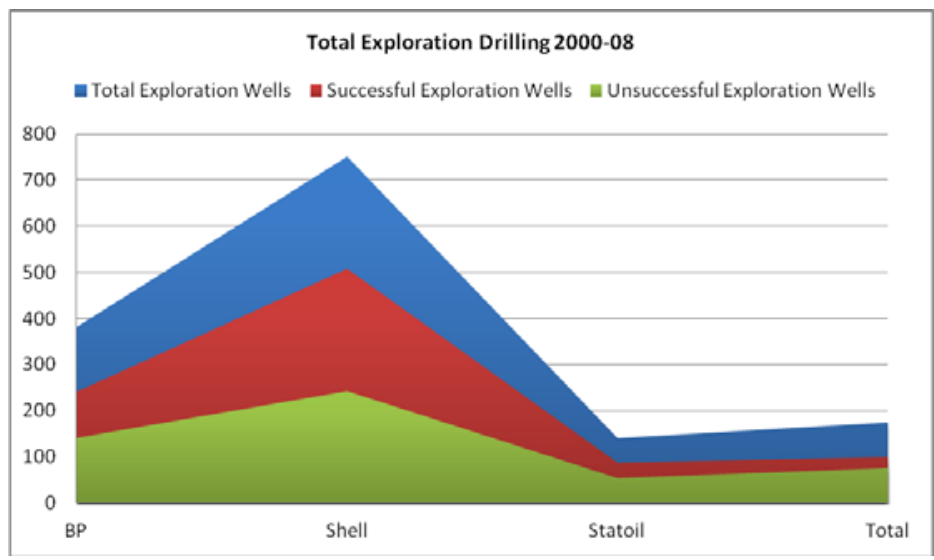

Since finding new reserves is only one part of what an oil and gas company has to be successful at, one has to look deeper at how successful they are at developing their assets. Figure 9 shows the cumulative development drilling activity of BP, Shell, Statoil and Total from 2000 to 2008, and we see interestingly that BP drilled over 700 more development wells than Shell. This could be attributed to a possible strategy of BP to acquire assets already discovered by smaller exploration companies and hence minimise its exposure to exploration stage risk or it could possibly mean that it needed to drill more wells in order to successfully develop its reserves. A possible confirmation of the latter 
can be seen in Figure 10, which shows that BP's development success rate was 96\%, less than Shell's leading performance of $99 \%$.

A similar argument can be said for Total, which had proportionately high development drilling relative to exploration drilling. We see from Figure 10 that Total's annual average success rate over the period was $89 \%$, the lowest of the four companies. This meant that it had a relatively higher number of unsuccessful development wells drilled which meant that it needed to drill more wells in order to successfully develop its reserves. Statoil, on the other hand, appeared to have been very lean with a total of only 435 development wells drilled but achieved an annual average success rate of $98 \%$, a close second to Shell's performance.

Figure 9 Total development drilling 2000-08 (see online version for colours)

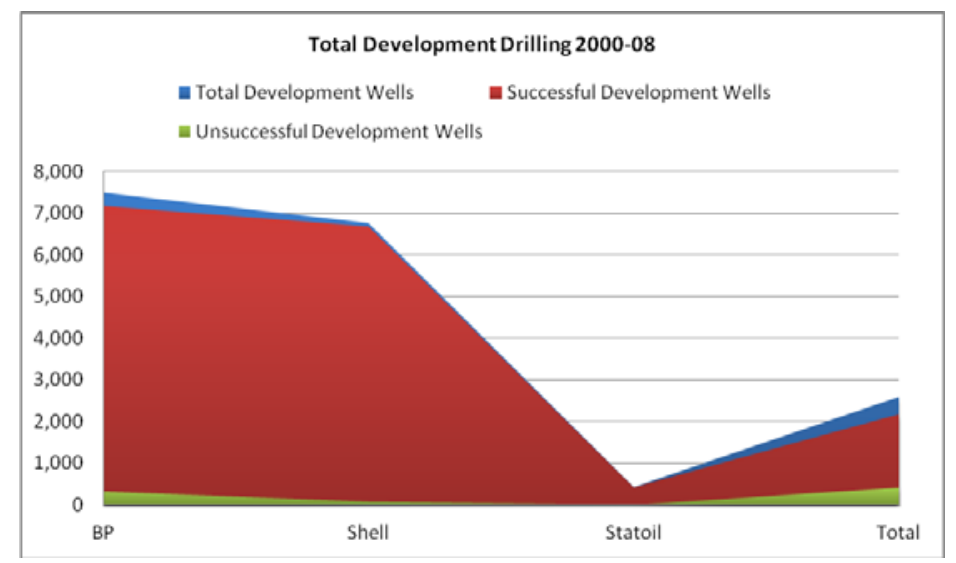

Figure 10 Annual average exploration and development success rate 2000-08 (see online version for colours)

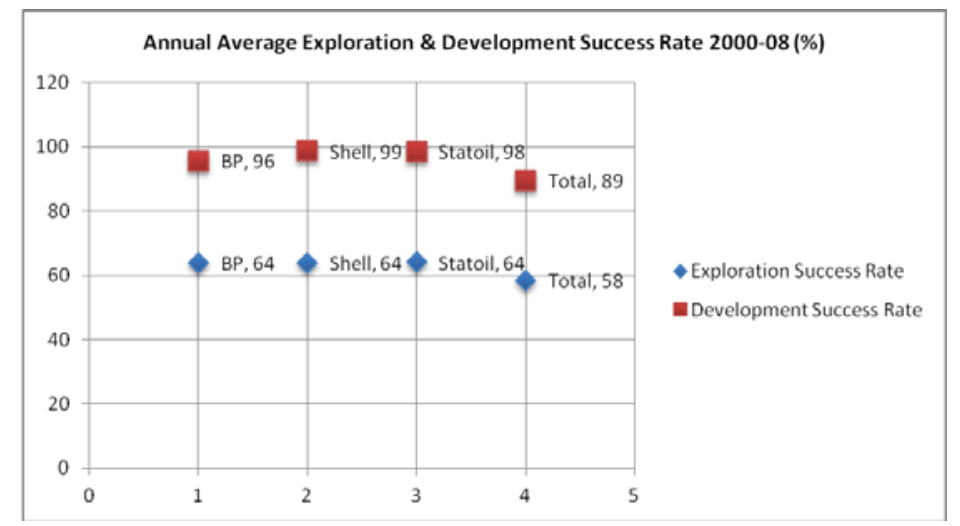

The knowledge-based resource findings for the companies analysed in this study are consistent with Grant (1996), which looked at the importance of knowledge application. Proxies that capture the level of knowledge application for the oil companies include the success rate of their drilling activities in both exploration and development. Shell, BP, 
and Statoil showed a consistent exploration drilling success rate with Shell being the best performer in development drilling.

It can be argued that the technical, creative, collaborative, and project management expertise that are required in successfully finding and developing new reserves are VRIN resources. They are valuable because the discovery and development of reserves are the core value-creating activities of oil and gas companies. But are they rare? To some extent one can argue that yes they are rare, because these companies build their technical expertise mostly through internal R\&D and patents, i.e. the knowledge creation part; and develop their creative, collaborative, and project management expertise through firm-specific configurations and processes, i.e., the knowledge application part. Theses skills and competencies are therefore not available to all companies. Are they in-imitable? Yes, because such proprietary technology and practices cannot be easily copied, competitors would have to invest and build their own capabilities, which would take time. Are they non-substitutable? This can be argued to be yes as well unless competitors outsource such activities, which if they pay a fair market price will eliminate any above-average returns. As a result, based on the analysis above, Shell was the best performer in finding and developing reserves and this is confirmed by their superior employee efficiency with the highest net income per employee.

\section{Discussion}

Oil and gas companies have played a dominant role in our lives for over a century in terms of being the single biggest provider of our energy needs for households; manufacturing as well as service companies; land, sea and air transport; and petrochemicals. From another dimension, they are some of the biggest companies in the world providing employment for hundreds of thousands of people and being high income-yielding investments for a number of pension funds. For example, BP and Shell during periods of high oil prices are the biggest companies, by market capitalisation, on

the FTSE and are sometimes the biggest income-generating stocks to a number of pension funds in the UK.

It is therefore worthwhile to deepen our understanding of oil and gas companies in terms of their operations and the key drivers and determinants for their successful performance. This study has looked at the major European oil and gas companies and provided a comparative analysis identifying the key measures, using the RBV framework, that have contributed to their success in the past and discussed how significant they will be for the future. A further extension of this study could be comparing these major European oil and gas companies to major oil and gas companies around the world, in particular US companies like ExxonMobil and Chevron, as well as national oil companies like Saudi Aramco, PDVSA, and Petronas.

The RBV defines two kinds of resources to be property-based and knowledge-based. Property-based resources generally refer to physical resources controlled by the firm and in the context of oil and gas companies they refer to physical oil and gas reserves, number of platforms for drilling and production, pipelines, number of tankers, number of refineries, number of service stations. In this study, we have used the measures of annual 
capital expenditure, annual changes in liquids and gas reserves, annual replacement ratios, and amount of refinery distillation capacity and number of service stations as proxies to capture the level of property-based resources at both upstream and downstream for the six companies.

Knowledge-based resources, on the other hand, is more subtle and refers to the intangible expertise and intellectual content within the firm including technical, creative and collaborative skills. In this study, we have used measures related to employee efficiency such as net income per employee and measures related to employee expertise such as the success rate of drilling exploration and development wells. The knowledge-based resource domain presents the most scope in widening and deepening this area for future research. Possible measures that could be looked at, data availability permitting include the amount of $R \& D$ expenditure for each company relative to their total revenue, net income, or on a per employee basis. A further measure could be the number of patents filed for and granted for each company, as this will give some insight into how successful their R\&D operations are. Another measure that could be useful is the cost per barrel of finding new reserves as well as production.

In relation to the literature, one can extend the argument put forward by Kim and Mahoney (2002) that property-based resources are important. In the context of upstream versus downstream property resources, one can investigate which one adds most value to the companies and in which particular environment. One can also test the argument put forward by Grant (1996) that even though knowledge application is important, it should not be the only focus at the detriment of knowledge creation. Since we have only looked at knowledge application through the proxies of exploration and development drilling success rates, if data permits the level of knowledge creation by these oil and gas companies can be investigated. For instance, data on intellectual property (IP) or proprietary knowledge within these companies and the amount of patents held could be useful proxies to test for the creation of knowledge. In addition, drawing from Russo and Fouts (1997), one can use proxies for environmental performance through carbon trading mechanisms and data on environmental disasters to test whether it does actually pay to be green.

There is therefore a need to understand which of these resources contribute significantly to a sustainable competitive advantage. As discussed earlier in the property-based and knowledge-based resource sections, firms with VRIN resources may achieve competitive advantages that can sustain above-average returns (Schmidt and Keil, 2013; Newbert, 2008; Barney, 1991). Since each of the four criteria are individually necessary but not sufficient conditions for a sustained competitive advantage (Wernerfelt, 2013; Dierickx and Cool, 1989), it is sometimes argued that it is very difficult, if not impossible, to identify resources that satisfy all the VRIN criteria and lead to competitive advantages. For the oil and gas companies analysed in this study, we have argued that access to capital is not a VRIN resource, but we have seen that the technical, creative, collaborative, and project management expertise developed and applied within these companies can to some extent be considered VRIN resources. They lead to superior exploration and development drilling and hence superior efficiency, evident in the case of Shell with the highest net income per employee. 


\section{Implications for management practice}

Drawing from the argument that knowledge-based resources will play an increasingly significant role in the future success of oil and gas companies, one can argue that a key area of focus as a driver of their performance is their employees, and in particular the effective management of their employees. It can be argued that it is only when technical and analytical skills are combined with a high level of personal and interpersonal awareness (for successful collaboration) is there a sound foundation for effective management. Further, one can argue that rational and calculative techniques are of greater value in a management context when the employees also understand how to 'manage' themselves.

This additional dimension to employee performance as a driver of firm performance refers to the employees' conduct, and the impact, both intended and unintended, that this has on others as well as their own effectiveness. When firms achieve increased effectiveness among their employees, this will translate to the employees accomplishing tasks with and through others more effectively as well as better addressing the continuous challenges of 'doing' management. Such challenges include developing the capacity of employees for rational decision-making, enhancing their ability to work effectively with and through others, and strengthening their discipline and awareness of their day-to-day conduct and its impact on their relationship with colleagues. This therefore involves a focus on areas such as culture, communication, and leadership.

As a result, some key themes relevant to management practice can be identified and should be addressed by oil and gas companies in order for them to develop the effectiveness of their employees, which we have argued, are a key knowledge-based resource that will play an increasingly significant and vital role in their future performance (Gardner et al., 2012; Nag and Gioia, 2012; Bollinger and Smith, 2001; Grant, 1997). These themes include effectively managing inter-cultural differences in teams in terms of analysing and coping with different cultural views and approaches, managing the dynamic interdependence of tasks and what this means for team and individual needs as they develop over time, managing the personal and interpersonal dimensions of leadership, managing different communication preferences and skills including active listening and how well teams give and receive feedback, and also managing how group cultures develop and its role in anxiety avoidance and problem-solving.

\section{Conclusions}

This paper has analysed, using the RBV framework, the two kinds of resources of the six major European oil and gas companies, and has compared their relative performance between 2000 and 2008. The resource measures analysed under property-based resources include annual capital expenditure, annual changes in liquids and gas reserves, annual replacement ratios, and the amount of refinery distillation capacity and number of service stations. Under knowledge-based resources, the paper analysed the number of employees and net income per employee, and the annual levels of drilling activity with the success rate in exploration and development drilling.

In this new epoch of increasing uncertainty and change in how we produce and consume energy, with considerations ranging from the irreversible decline in global oil 
reserves, high oil prices, high technology requirements, and perhaps above all the global initiative to limit carbon emissions and adopt cleaner energy supplies, the increasingly pertinent question is how will oil and gas companies survive over the next century? One can argue that, based on the RBV framework, they will have to rely more on their knowledge-based resources in such times of unprecedented uncertainty and change. They will inevitably in the long run have to move beyond petroleum towards cleaner renewable energy.

What does this mean for policy-making across Europe at both the governmental and supranational levels? It is argued that in order for these major European oil and gas to be competitive in the long run, it is important that they continue to develop their knowledge-based resources by investing in knowledge creation activities such as increased R\&D as well as investing in knowledge application through training and adequate human capital development. Hence, there are key economic and social policy-making decisions to be made in order to facilitate and stimulate the development of the knowledge-based resources within these companies in order for them to stay competitive, with the long-term vision of developing and adopting cleaner energy sources.

\section{References}

Barney, J. (1991) 'Firm resources and sustained competitive advantage', Journal of Management, Vol. 17, No. 1, pp.99-120.

Barney, J. (2001) 'Is the resource-based 'view' a useful perspective for strategic management research? Yes', Academy of Management Review, Vol. 26, No. 1, pp.41-56.

Bollinger, A. and Smith, R. (2001) 'Managing organizational knowledge as a strategic asset', Journal of Knowledge Management, Vol. 5, No. 1, pp.8-18.

Clasen, J. (2004) 'Defining comparative social policy', in Kennett, P. (Ed.): A Handbook of Comparative Social Policy, Edward Elgar Publishing, Cheltenham.

Deutsch, K. (1987) 'Prologue: achievements and challenges in 2000 years of comparative research', in Dierkes, M., Weiler, H. and Antal, A. (Eds.): Comparative Policy Research: Learning from Experience, St. Martin's Press, New York.

Dierickx, I. and Cool, K. (1989) 'Asset stock accumulation and sustainability of competitive advantage', Management Science, Vol. 35, No. 12, pp.1504-1511.

Gardner, H., Gino, F. and Staats, B. (2012) 'Dynamically integrating knowledge in teams: transforming resources into performance', Academy of Management Journal, Vol. 55, No. 4, pp.998-1022.

Grant, R. (1996) 'Toward a knowledge-based theory of the firm', Strategic Management Journal, Vol. 17, No. S2, pp.109-122.

Grant, R. (1997) 'The knowledge-based view of the firm: implications for management practice', Long Range Planning, Vol. 30, No. 3, pp.450-454.

Guillen, M. (2000) 'Business groups in emerging economies: a resource-based view', Academy of Management Journal, Vol. 43, No. 3, pp.362-380.

Kim, J. and Mahoney, J. (2002) 'Resource-based and property rights perspectives on value creation: the case of oil field unitization', Managerial and Decision Economics, Vol. 23, Nos. 4-5, pp.225-245.

Levy, D. and Kolk, A. (2002) 'Strategic responses to global climate change: conflicting pressures on multinationals in the oil industry', Business and Politics, Vol. 4, No. 3, pp.275-300. 
Miller, D. and Shamsie, J. (1996) 'The resource-based view of the firm in two environments: the Hollywood film studios from 1936 to 1965', Academy of Management Journal, Vol. 39, No. 3, pp.519-543.

Nag, R. and Gioia, D. (2012) 'From common to uncommon knowledge: foundations of firm-specific use of knowledge as a resource', Academy of Management Journal, Vol. 55, No. 2, pp.421-457.

Newbert, S. (2008) 'Value, rareness, competitive advantage, and performance: a conceptual-level empirical investigation of the resource-based view of the firm', Strategic Management Journal, Vol. 29, No. 7, pp.745-768.

Russo, M. and Fouts, P. (1997) 'A resource-based perspective on corporate environmental performance and profitability', Academy of Management Journal, Vol. 40, No. 3, pp.534-559.

Schmidt, J. and Keil, T. (2013) 'What makes a resource valuable? Identifying the drivers of firm-idiosyncratic resource value', Academy of Management Review, Vol. 38, No. 2, pp.206-228.

Wernerfelt, B. (1984) 'A resource-based view of the firm', Strategic Management Journal, Vol. 5, No. 2, pp.171-180.

Wernerfelt, B. (1995) 'The resource-based view of the firm: ten years after', Strategic Management Journal, Vol. 16, No. 3, pp.171-174.

Wernerfelt, B. (2013) 'Small forces and large firms: foundations of the RBV', Strategic Management Journal, Vol. 34, No. 6, pp.635-643. 